\title{
EFEITO “IN VITRO” DE PRODUTOS COMERCIAIS SOBRE O CRESCIMENTO DE Fusarium solani F.sp. piperis
}

\author{
Bianca Ferreira Santos ${ }^{1}$ \\ Bruna Carminate ${ }^{2}$ \\ Winicius Botelho de Souza ${ }^{3}$ \\ Alex Silva Lima ${ }^{4}$ \\ Verônica D'Addazio ${ }^{5}$ \\ Marcelo Barreto da Silva ${ }^{6}$
}

Resumo: A pimenta-do-reino (Piper nigrum) é muito suscetível ao fungo Fusarium solani f. sp. piperis Alb., causador de grandes danos à cultura, reduzindo o período útil de exploração da cultura para apenas quatro anos ou menor, dependendo do nevel de infecção. $O$ objetivo do trabalho foi avaliar a atividade antifúngica in vitro de um fertilizante com ação bioestimulante (Eurofit Max) e um fungicida sistêmico do grupo fosfonato frente ao fungo Fusarium spp. Foi prepara uma solução com os produtos a serem testasdos nas concentraçoes de 2000, 1000, 500 e 250 ppm, a solução foi adicionada em $30 \mathrm{ml}$ de BDA fundente estéril e posteriormente transferido para o centro da placa um disco de $6 \mathrm{~mm}$ de diâmetro de micélio do fungo e incubado em B.O.D. a $25 \pm 1^{\circ} \mathrm{C}$ por 12 dias. O produto testado com ação bioestimulante (Eurofit Max $\left.{ }^{\circledR}\right)$ se demostra eficiente na inibição do crescimento in vitro do fungo Fusarium solani $f$. sp. piperis Alb. Palavras-chave: Fusarium; Controle alternativo; Pimenta do reino; Ascophyllum nodosum.

\footnotetext{
${ }^{1}$ Agronomia/Universidade Federal do Espírito Santo, Centro Universitário Norte do Espirito Santo, Brasil. E-mail: biancasantos123@hotmail.com.

${ }^{2}$ Agronomia/Universidade Federal do Espírito Santo, Centro Universitário Norte do Espirito Santo, Brasil. E-mail: brunabcarminate@hotmail.com.

${ }^{3}$ Agronomia/Universidade Federal do Espírito Santo, Centro Universitário Norte do Espirito Santo, Brasil. E-mail: winicius07@hotmail.com.

${ }^{4}$ Agronomia/Universidade Federal do Espírito Santo, Centro Universitário Norte do Espirito Santo, Brasil. E-mail: alexlima010@yahoo.com.br.

${ }^{5}$ Agronomia/Universidade Federal do Espírito Santo, Centro Universitário Norte do Espirito Santo, Brasil. E-mail: veronicadaddazio@yahoo.com.

${ }^{6}$ Professor Titular/Universidade Federal do Espírito Santo, Centro Universitário Norte do Espirito Santo, Brasil. E-mail: marcelobarretodasilva@gmail.com.
} 